\title{
The Empirical Research on the Impact of Pro- Environmental Factors on the Financing Cost of Green Bond
}

Chunlian Zhang ( $\sim 2201810044 @ s t u . j x u f e . e d u . c n$ )

Jiangxi University of Finance and Economics https://orcid.org/0000-0002-8753-7331

\section{Ziming Liu}

Jiangxi University of Finance and Economics

Yuqing Zeng

Jiangxi University of Finance and Economics

Ou Yang

University of Melbourne

\section{Research Article}

Keywords: pro-environmental green bond financing cost

Posted Date: September 7th, 2021

DOI: https://doi.org/10.21203/rs.3.rs-760150/v1

License: (c) (i) This work is licensed under a Creative Commons Attribution 4.0 International License.

Read Full License 


\title{
The Empirical Research on the Impact of Pro-Environmental Factors on the Financing Cost of Green Bond
}

\author{
Chunlian Zhang ${ }^{1}$, Ziming Liu ${ }^{2 *}$, Yuqing Zeng ${ }^{3}$, Ou Yang ${ }^{4}$ \\ 1. School of Finance, Jiangxi University of Finance and Economics, Nanchang \\ 330013, Jiangxi, China; 2201810044@ stu.jxufe.edu.cn \\ 2. School of Finance, Jiangxi University of Finance and Economics, Nanchang \\ 330013, Jiangxi, China;2201920421@ @stu.jxufe.edu.cn \\ 3. School of Law, Jiangxi University of Finance and Economics, Nanchang 330013, \\ Jiangxi, China;2201921658@stu.jxufe.edu.cn \\ 4.Melbourne Institute of Applied Economic and Social Research, University of \\ Melbourne, Australia; ou.yang@unimelb.edu.au \\ *Correspondence: $2201920421 @$ stu.jxufe.edu.cn; Tel.: 18789028100
}

\begin{abstract}
Green bonds are an important part of green finance and a significant financing method for enterprises to make socially responsible investments. This thesis analyzes the impact of proenvironmental factors on the financing cost of green bonds by the data of green bonds issued from 2016 to 2020 . The results show that the better the environmental performance of the issuer's region, the lower the financing cost of green bonds, and the third-party certification reduces the financing cost of green bonds. Further research shows that high pollution areas and high pollution industries enhance the punitive role of environmental pollution financing. Regional environmental performance mainly affects the financing cost of green bonds through tax suppression mechanism and credit penalty mechanism, while third-party certification affects the financing cost of green bonds through tax relief mechanism and financing channel mechanism. This paper provides empirical evidence and policy inspiration for reducing the financing cost of issuing green bonds and promoting the perfection of the green bond system.
\end{abstract}

Key Words: pro-environmental green bond financing cost

JEL: G18 G30 Q50

\section{Declarations}

Ethics approval and consent to participate: Not applicable

\section{Consent for publication: Not applicable}

Availability of data and materials: The datasets used and analyzed during the current study are available from the corresponding author on reasonable request.

Competing interests: The authors declare that they have no competing interests.

Funding:Not applicable

Authors' contributions:Ziming Liu analyzed and interpreted the Green Bond data regarding the financing cost. Yuqing Zeng analyzed and interpreted the data of ProEnvironmental Factors. Chunlian Zhang was a major contributor in writing the manuscript and collecting the data. Ou Yang translated the manuscript. All authors read and approved the final manuscript.

Acknowledgments: We thank all the editors for permitting the use of the vineyards where this research was done. 


\section{Introduction}

In December 2015, the People's Bank of China issued Announcement on Issues Related to the Issuance of Green Financial Bonds, and Chinese National Development and Reform Commission issued the Guidelines on the Issuance of Green Bonds, which basically formed Chinese green bond issuance system and marked the beginning of the development of the green bond market. By the end of 2020, the size of Chinese green bond market had reached 278.662 billion yuan, and the number of issuance is more than 2019. The total size of labeled green bonds exceeding 1.4 trillion yuan, however, the issuance of non-labeled green bonds totaled 1.67 trillion yuan, up nearly threefold year on year ${ }^{\mathbb{1}}$

Green bonds are corporate bonds funding for green, circular and low-carbon sustainable development projects, such as the energy conservation and emissions reduction technology reform, green urbanization, clean and efficient use of energy, new energy development and utilization, recycling economy development, water resources saving and unconventional water resources development and utilization, pollution control, ecological forestry, energy conservation, environmental protection, low carbon industry, ecological civilization demonstration experiment in advance, pilot demonstration and so on. ${ }^{2}$ There are so many factors affecting the financing cost of green bonds. In addition to the general factors such as the issuer's credit rating, bond maturity, market interest rate and so on, there are also specific factors unique to green bonds, such as the environmental conditions of the issuer's area and third-party certification, which are called pro-environmental factors in this thesis.

As a special kind of bonds, green bonds also have the general properties of bonds. Scholars have abundant studies on the nature of bonds, such as issuing pricing, credit risk, information quality and financing structure. The existing literature divides the factors affecting bonds into macro economy and economic policy (Zhou Hong et al. 2011; Ba et al. 2019), financial market environment and financial system (Jin 2010; Yang and Pan 2019; Meng and Yin 2019), characteristics and terms of bonds (Tan et al. 2008; Ai et al. 2015; Bazzana et al. 2018) and the characteristics and behavior of bond issuers (Chen et al. 2011; Shi and Liu 2019; Fang et al. 2013). At present, there are the following mainly four parts in the research on green bonds: First, the research on the relevant definition, nature and status quo of green bonds. For this part, most scholars get relevant conclusions through theoretical analysis, and only some scholars simply use the issuance data of green bonds (Labaat and White 2002; Jin and Han 2016). Second, Suggestions on the development and system of green bond market, scholars studying this part mainly conduct some quantitative analysis by improving the information disclosure system, "labeling" issuance system and third-party certification system of green bonds (Clapp 2014). Third, the research on the relationship between green bonds and other assets, they mainly analyse the prices between other financial products and green bonds, such as the price of conventional corporate bonds (Juan and Andrea 2018), "black bonds" (David 2019) and stocks (Wang et al. 2020). Fourth, study on the motivation of issuing green bonds. On the one hand, it can promote energy conservation and emission reduction (Paranque and Revelelli 2017; Elettra and Rossella 2021). On the other hand, it can encourage financing entities to issue green bonds by increasing revenue and reducing costs (Tang and Zhang 2020; Ma et al. 2021).

By now, the research on the financing cost of green bonds mainly starts from the

\footnotetext{
(1) The data comes from China's Green Bond Market Status Report 2019, jointly compiled by the Climate Bond Initiative (CBI) and the Central Government Bond Deputation and Clearing Co., Ltd.

${ }^{2}$ From Guidelines on the Issuance of Green Bonds.
} 
market factors, and analyzes the characteristics of the green bond market, the relationship between the relevant market factors and the financing cost of green bonds. Mathews and Kiney (2010) studied the characteristics, scale, expected risk and other general factors of the issuing enterprises. Febi et al. (2018) and Olivier (2018) researched the relationship between the liquidity of green bonds and the financing cost, and concluded that the stronger the liquidity of green bonds, the lower the financing cost. Gao and Ji (2018) found in their research that the financial status of issuers has no influence on the financing cost of green bonds, while the higher the rating of the issuer, the lower the financing cost of green bonds. Diaz and Escribano (2021) analyzed the differences between green bonds issued by green energy companies and non-green energy companies, whose results showed that the ESG (environment, social responsibility and corporate governance) standard and credit rating of the company had an inverse relationship with the financing cost of green bonds. With the development of green bond market, pro-environmental factors have gradually attracted the attention of bond issuers, bond investors, government departments and regulatory authorities. So more and more scholars have combined the environmental information contained in green bond with its financing cost to conduct research. Eichholtz et al. (2019) found that the bonds issued by the real estate trust with environmental certification in the market have lower credit spreads, lower environmental risks and lower financing costs. Wang et al. (2020) found that the stronger the social responsibility and the higher the social reputation of the issuer, the lower the financing cost of the green bond issued. Meanwhile, the more fully the green bond information is disclosed, the corresponding financing cost will be reduced. The research of Pham and Huynh (2020) shows that investor attention of environmental information of issuers is closely related to the financing cost of green bonds.

We selected 543 green non-financial bonds issued from 2016 to 2020 that were suitable for the definition of Guidelines on the Issuance of Green Bonds to analyze the impact of pro-environmental factors on the financing cost of green bonds. It is found that the lower the level of environmental pollution in the region where the issuer is located, the lower the financing cost of green bonds; Third-party certification reduces the financing cost of green bonds. The contribution of this paper is adopt an proenvironmental perspective to explore for the impact of pro-environmental factors on the financing cost of green bonds, and to analyze the asymmetry of this influence under different moderating effects and the specific influencing mechanism.

The rest of this thesis is arranged as follows. Section 2 puts forward research hypothesis by the theoretical analysis. Section 3 describes research design including data source, variable definition and model design. In section 4, we present the empirical results and analysis, and the robustness test is put in section 5 . Then, we make further analysis, that is the moderating effect and the mechanism analysis which are in section 5 and 6 separately. The last section shows research conclusions.

\section{Theoretical analysis and research hypothesis}

\section{$131 \quad 2.1$ Regional environmental performance}

132 For an area, the higher the level of pollution, the higher the cost of treatment. High 133 pollution will also attract the attention of the central government, leading to the central 134 government to reduce the fiscal bias or related investment, forcing the local government 135 to pay more attention to environmental protection and increase the punishment for 136 pollution, which makes the development of local enterprises subject to more 137 administrative restrictions. The increase of environmental risk and political risk will 
lead to the increase of the issuance cost, that is, increase the financing cost of the local issuance of green bonds. On the contrary, the stronger the local environmental awareness, the more suitable it is for the goal of pro-environmental, the more investors will be attracted, and the higher the environmental protection degree will be more in line with the national policy, which will be subject to more fiscal bias, so the financing cost of local green bonds will be reduced. At the same time, according to the theory of ESG, when regional environment degrades, enterprises will face greater environmental risks, the benefit of the parties involved will be damaged, the enterprise competitiveness has also dropped, the enterprise value to fall, which will increase difficulty that enterprises access to capital, the credit risk and liquidity risk will increase, credit spreads will be bigger, so it to issue bonds financing costs will rise. At present, there are few literatures on the relationship between regional environmental performance and bond financing cost, but the existing scholars have given a consistent view on this relationship: Painter (2020) 's study shows that regions affected by climate change need to pay more costs to issue long-term municipal bonds, which will increase their issuing interest rate; Cui et al. (2019) found in their research that the more investment in local pollution control, the better the local pollution control effect and environmental performance, the lower the environmental cost faced by enterprises, and the lower the financing cost of environmental protection. Conversely, the less region invests in pollution control, the higher the level of local pollution, the worse its environmental performance, the higher the environmental costs faced by enterprises, and the higher its financing costs. Zhang et al. (2019) found that the greater the pressure of regional environmental governance, the easier it is to force local officials to urge enterprises to invest in environmental protection. The above studies show that regional environmental differences will affect the behavior of economic entities, and the degree of environmental pollution will affect the cost of issuing bonds for enterprises. In other words, the better the local environmental performance, the lower the financing cost of issuing green bonds. Based on the above analysis, we propose the following hypotheses:

H1: The better the region's environmental performance, that is to say, the lower the level of environmental pollution, the lower the financing cost of issuing green bonds.

\subsection{Third-party certification}

Third-party certification, also known as the second party opinion, is the approval and certification of green bond information disclosure by independent third-party institutions as well as the assessment and disclosure of the environmental effects faced by the issuer. Therefore, third-party certification can reduce information asymmetry, more objectively reflect the pro-environmental characteristics of green bonds and effectively show whether green bonds are "green-wash" or "true green". According to Notice on the Pilot Program of Green Bonds issued by Shanghai Stock Exchange and Shenzhen Stock Exchange in 2016, "labeled" green bonds are green bonds are found for the industries in which the funds raised by the bonds conform to Catalogue of Green Bond Support Projects, as well as, are accepted, reviewed and uniformly labeled by Chinese National Development and Reform Commission, Shanghai Stock Exchange and Shenzhen Stock Exchange. The national policy does not enforce "labeling" of green bonds, but does encourage. The introduction of the third-party certification make "label" more authentic, can reflect more reality of the investment projects by green bonds to raise funds, reduces the subjectivity of "label", enhance the credibility of the green securities information disclosure, enhance the green bond credit and accord with the requirement of ESG rating, which reduces the issue facing the enterprises credit risk and liquidity risk. Hence the credit spreads of these green bonds will drop, which will 
reduce the issuing cost of green bonds. However, the "labeled" green bonds without third-party certification, without more objective information certification, cannot gain the trust of investors, do not reflect the principles of ESG, and have no substantial reduction in credit risk and liquidity risk, which will increase the financing costs of green bonds. He et al. (2016) found in their research that financial certification of bonds can alleviate information asymmetry and reduce bond financing costs. The financing projects of green bonds are closely related to environmental risks. Third-party certification can more effectively reflect information related to the environment, improve the information transparency of green bonds, and thus gain recognition from more investors, which will help reduce their financing costs. Jiang and Fan (2020), Yang and Shi (2020) found that the "label" issue does not reduce the financing cost of green bonds. Furthermore "label" green bonds without the third-party certification have greater "green-wash" risk that increase the financing cost of green bonds. But the green subsidy and third-party certification can reduce the financing cost of green bonds. Based on the above analysis, we state second hypotheses:

$\mathrm{H} 2$ : The financing cost of green bonds with third-party certification is lower than that without third-party certification.

\section{Research design}

\subsection{Sample selection and data source}

According to the Notice on the Pilot Business of Green Corporate Bonds issued by the Shanghai Stock Exchange and Shenzhen Stock Exchange, we selected the sample bonds that meet the definition of "green bonds" from 2016 to 2020. We have carried out the following three aspects of processing based on the actual situation: (1) In the duration of the bond, the issuer may issue additional bonds. We eliminate the additional bonds and take the original bonds as the research object. (2) There is a phenomenon that corporate bonds are issued in one place and managed in two places, but two bonds are actually one bond. Therefore, we exclude the green corporate bonds listed and traded in the interbank market in cross-market trading, and only retain the green bonds listed and traded in the exchange market. (3) We exclude some private bonds with undisclosed interest rate, financial bonds and incomplete data.

After the adjustment and processing of the above three aspects, we finally obtained the observed sample values of 543 non-financial green bonds. In order to eliminate the influence of extreme values, we conducted a bilateral $1 \%$ Winsorize for the main variables in the paper.

We collect the characteristic information of sample bonds and the financial characteristics information of issuers from the Wind database, the data of national debt issuance and stock market yield from the CSMAR database, the data of regional environment, economy and financial status from the statistical yearbooks of all provinces and the macro-economic status from the statistical database of China Economic Network.

\subsection{Variable definition}

\subsubsection{Credit spread}

Based on the Nelson-Siegel model (Nelson and Siegel 1987), we selected the financing cost proxy variable consistent with the literature of Gao and Ji (2018), Jiang and Fan (2020), namely, the credit spread between green bonds and the yield of 
government bonds of the same maturity:

$$
r_{g p}=r_{b}-r_{g}
$$

234 where $r_{g p}$ represents the credit spread of green bonds, $r_{b}$ indicates the interest rate of green bonds issued, $r_{g}$ dontes the average interest rate of national debt of the same year with green bonds (If not, the average interest rate of national debt of the adjacent years is taken.). This proxy variable not only reflects the financing cost of green bonds after deducting the risk-free interest rate of the same issuing period, but also reflects the interest rate risk and market risk faced by investors as well as the risk preference of investors.

\subsubsection{Regional environmental pollution index}

We refer to the regional environmental pollution index PI used by Li and Tao (2012), $\mathrm{Su}$ and Lian (2018) as the proxy variable of regional environmental performance, and the specific construction steps are as follows:

First, we chose the emissions of four types of pollutants to measure the pollution situation in the region that are industrial sulfur dioxide, industrial smoke (powder) dust, industrial wastewater and industrial solid waste.

Second, to construct a regional environmental pollution index, we calculated the pollution situation two years before the issuance of green bonds. The specific calculation steps are as follows:

First of all, we calculate regional pollutant emissions per unit of industrial output:

$$
U_{i j}=\frac{\text { Pollution }_{i j}}{\operatorname{GIP}_{j}}
$$

where Pollution $_{i j}$ denotes the discharge amount of the $i$ pollutant in the $\mathrm{j}$ region (province, autonomous region or municipality), GIP $P_{j}$ represents the total industrial output value of district $j .(i=1,2, \cdots, 4 ; j=1,2, \cdots, 31)$

Second, the emissions of per unit of industrial output of the $i$ pollutant in the same area are linearized:

$$
e n v_{i j}=\sum_{i=1}^{4} \frac{U_{i j}-\min \left(U_{i j}\right)}{\max \left(U_{i j}\right)-\min \left(U_{i j}\right)}
$$

Where $U_{i j}$ denotes the emissions of per unit of industrial output of the $i$ pollutant in the $\mathrm{j}$ region, $\max \left(U_{i j}\right)$ and $\min \left(U_{i j}\right)$ represent the maximum and minimum of the emissions of per unit of industrial output of the $i$ pollutant in each province in the current year, respectively, and $e n v_{j}$ represents the normalized value.

Then, the standardized value of emissions per unit of industrial output of pollutants in the same area is added up:

$$
E N V_{j}=\sum_{i=1}^{4} e n v_{i j}
$$

Where $e n v_{i j}$ denotes the normalized value of the emissions of per unit of industrial output of the $i$ pollutant in the $\mathrm{j}$ region, $E N V_{j}$ represents the total of standardized values of the emissions of per unit of industrial output for all pollutants in the $\mathrm{j}$ region.

$$
(i=1,2, \cdots, 4 ; j=1,2, \cdots, 31)
$$

Finally, on the basis of the sum of the standardized values of the emission per unit of industrial output value of all pollutants in the region, a normalization is carried out again to obtain the environmental pollution index $P I$ :

$$
P I_{j}=\frac{E N V_{j}-\min \left(E N V_{j}\right)}{\max \left(E N V_{j}\right)-\min \left(E N V_{j}\right)}
$$

Where $E N V_{j}$ represents the total of standardized values of the emissions of per unit of industrial output for all pollutants in the $\mathrm{j}$ region, $\max \left(E N V_{j}\right)$ and $\min \left(E N V_{j}\right)$ represent 
the maximum and minimum of the total of standardized values of the emissions of per unit of industrial output for all pollutants in each province in the current year, $P I_{j}$ stands for the standardized value, and the regional pollution index.

Thirdly, according to the regional environmental pollution index, the paper divides the area into high-pollution area and low-pollution area. The standard and result are shown in Table 1.

Table1 Results of the division of environmental pollution areas

\begin{tabular}{lccc}
\hline Year & $\begin{array}{c}\text { The mean of Pollution } \\
\text { Index }\end{array}$ & Highly contaminated areas & Lowly contaminated areas \\
\hline 2010 & 36.49211 & 11 & 20 \\
\hline 2011 & 26.44338 & 9 & 22 \\
\hline 2012 & 23.15550 & 11 & 20 \\
\hline 2013 & 24.86522 & 9 & 22 \\
\hline 2014 & 25.06984 & 7 & 22 \\
\hline 2015 & 23.97244 & 9 & 22 \\
\hline 2016 & 10.39566 & 9 & 21 \\
\hline 2017 & 8.507723 & 10 & 19 \\
\hline 2018 & 6.001841 & 12 & \\
\hline
\end{tabular}

In this paper, the Environmental Pollution Index of 31 provinces (municipalities and autonomous regions) is calculated as average value, and the areas above the average value are recorded as high pollution areas, otherwise as low pollution areas.

\subsubsection{Control variable}

\section{1. characteristic variable of the bonds}

According to the literature review and theoretical basis, this paper selects the bond issue term, the bond issue scale and the bond repurchase right as the measurement index of the bond liquidity risk, and selects the bond credit rating as the measurement index of the bond credit risk, to control the impact of liquidity risk and credit risk on bond credit spreads. (Shi and Tian 2016; He et al. 2016; Olivier 2019) the specific indicators are as follows: first, the scale of bond issuance (scale), the scale of bond issuance is generally matched with the demand for funds and their own assets, and there is no clear positive or negative relationship with the financing cost; Secondly, the maturity of bonds, the longer the maturity of bonds, the greater the risk and the higher the cost of financing. Thirdly, the credit rating of bonds (rank), which is considered to reflect the specific credit of bonds, generally speaking, the higher the bond rating, the bond repurchase right is the right granted by the bond contract to the bond issuer. When the interest rate falls, the bond issuer can buy back the bond from the bond investor, therefore, there is a positive correlation with the financing cost.

According to the literature review and theoretical basis, this paper selects the bond issue term, the bond issue scale and the bond repurchase right as the measurement index of the bond liquidity risk, and selects the bond credit rating as the measurement index of the bond credit risk, to control the impact of liquidity risk and credit risk on bond credit spreads. (Shi and Tian 2016; He et al. 2016; Olivier 2019) the specific indicators are as follows: first, the scale of bond issuance (scale), the scale of bond issuance is generally matched with the demand for funds and their own assets, and there is no clear positive or negative relationship with the financing cost; Secondly, the maturity of bonds, the longer the maturity of bonds, the greater the risk and the higher the cost of financing. Thirdly, the credit rating of bonds (rank), which is considered to reflect the specific credit of bonds, generally speaking, the higher the bond rating, the bond repurchase right is the right granted by the bond contract to the bond issuer. When the interest rate falls, the bond issuer can buy back the bond from the bond investor, therefore, there is a positive correlation with the financing cost. 
2. Financial characteristic variables of the bond issuers

The financial characteristic variable of the bond issuer is mainly used to measure the ability to repay the debt, that is, the credit risk of the enterprise, but it can also reflect the capital demand degree of the enterprise from another angle, thus the liquidity risk that the enterprise faces. The financial characteristic variables of bond issuers in this paper mainly include Yield valve(roe), EBIT(ebit), leverage (leverage) and net cash ratio(fund). Generally speaking, the increase of the first two profitability indicators indicates that the increase of the profitability of the enterprise and the decrease of the default probability will strengthen the enterprise's credit and reduce the enterprise's financing cost, while the higher the asset-liability ratio, the greater the credit risk and the higher the financing cost, the larger the proportion of cash flow generated by fund raising, the higher the cost of fund raising, the higher the cost of fund raising. (Hong and Zheng 2014; Wang et al. 2020).

3. Macroeconomic variables

Macro-economic factors and macro-economic policies are the important factors that affect the bond credit spread, which leads to the change of bond financing cost. Therefore, this paper selects GDP growth rate $(G D P)$ and Shanghai interbank offered rate (shibor) as the agent variables of macroeconomic and monetary policies respectively. See Febi et al.(2018), this article selects the Shanghai Stock Index annualized yield (index) to control the stock market to the green bond market influence.

In addition, this paper adds the virtual variables of year and industry, the virtual variables of year are set according to the convention, and the industry variables are set according to the "Industry Classification standard of listed companies" issued by the CSRC in 2012, to control for year and industry fixed effects; added a robust standard error for bond types, wind bonds are classified into corporate bonds, corporate bonds, asset backed securities, directional instruments, medium term notes, project income notes, exchangeable bonds and short term financing notes to ensure the robustness of the regression.

Table 2 Variable definition

\begin{tabular}{|c|c|c|c|c|}
\hline \multicolumn{2}{|c|}{$\begin{array}{c}\text { Variable } \\
\text { classification }\end{array}$} & $\begin{array}{l}\text { Variable } \\
\text { symbol }\end{array}$ & Variable name & Variable description \\
\hline \multicolumn{2}{|c|}{$\begin{array}{l}\text { Dependent } \\
\text { variable }\end{array}$} & $r_{g p}$ & $\begin{array}{l}\text { credit spreads on green } \\
\text { bonds }\end{array}$ & $r_{g p}=r_{b}-r_{g}$ \\
\hline \multirow{2}{*}{\multicolumn{2}{|c|}{$\begin{array}{l}\text { Core } \\
\text { explanatory } \\
\text { variable }\end{array}$}} & \multirow[b]{2}{*}{ certificate } & $\begin{array}{l}\text { regional Environmental } \\
\text { Pollution Index }\end{array}$ & Use two-phase lag $(t-2)$ \\
\hline & & & third party authentication & $\begin{array}{l}\text { Third party authentication takes } 1 \text {, } \\
\text { otherwise take } 0\end{array}$ \\
\hline \multirow{6}{*}{$\begin{array}{l}\text { Control } \\
\text { variable }\end{array}$} & \multirow{3}{*}{$\begin{array}{l}\text { Bond } \\
\text { characteri- } \\
\text { stics }\end{array}$} & $\begin{array}{c}\text { scale } \\
\text { maturity }\end{array}$ & $\begin{array}{l}\text { size of bond issue } \\
\text { bond maturity }\end{array}$ & $\begin{array}{l}\text { in units of RMB } 100 \text { million } \\
\text { in units of years }\end{array}$ \\
\hline & & rank & bond rating & $\begin{array}{l}\mathrm{AAA}=6, \mathrm{AA}+=5, \mathrm{AA}=4, \mathrm{AA}-=3, \\
\mathrm{~A}+=2, \mathrm{~A}-=1, \text { unrated or missing } \\
\text { means } 0\end{array}$ \\
\hline & & putoption & bond repurchase right & $\begin{array}{l}\text { With a bond call option means } 1 \text {, } \\
\text { otherwise means } 0\end{array}$ \\
\hline & \multirow{3}{*}{$\begin{array}{l}\text { Principal } \\
\text { characteri- } \\
\text { stics of } \\
\text { bonds }\end{array}$} & roe & yield valve & Use one-phase lag $(\mathrm{t}-1)$ \\
\hline & & ebit & EBITDA & $\begin{array}{l}\text { Use one-phase lag ( } t-1) \text {, in units of } \\
\text { RMB } 100 \text { million }\end{array}$ \\
\hline & & leverage & ratio of assets to & Use one-phase lag $(\mathrm{t}-1)$ \\
\hline
\end{tabular}




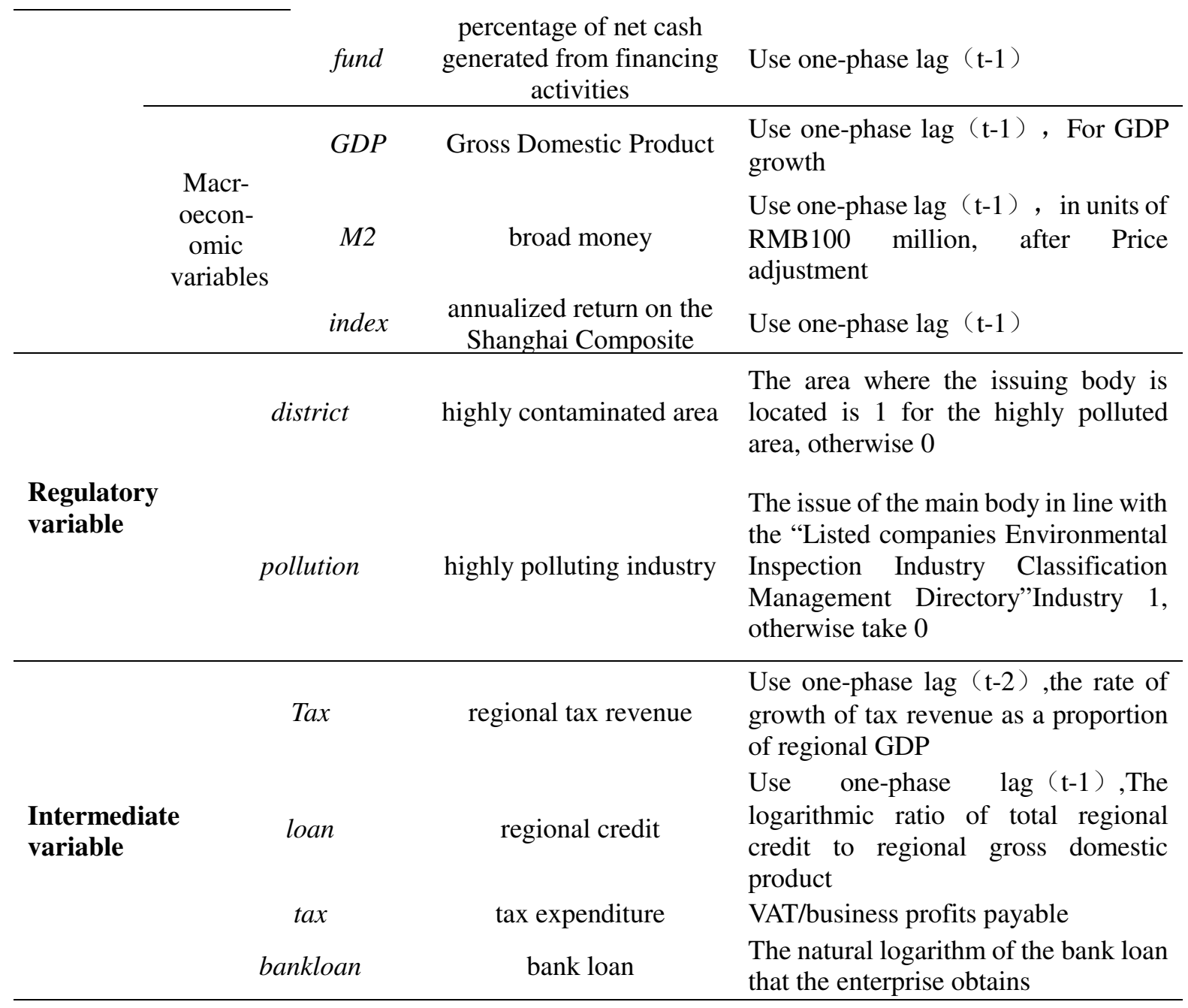

\subsection{Model design}

Based on the selected dependent variables, independent variables, control variables, regulatory variables, and intermediate variables, the following baseline regression models are established to test the basic hypotheses $\mathrm{H} 1$ and $\mathrm{H} 2$ :

$$
\begin{aligned}
& r_{g p i t}=\alpha_{0}+\alpha_{1} P I_{i t-2}+\varepsilon_{i t} \\
& r_{g p i t}=\beta_{0}+\beta_{1} \text { certificate }_{i t}+\varepsilon_{i t} \\
& r_{g p i t}=\gamma_{0}+\gamma_{1} P I_{i t-2}+\gamma_{2} \text { certificate }_{i t}+\gamma_{C} X_{i t}+\varepsilon_{i t}
\end{aligned}
$$

Where $r_{\text {gpit }}$ represents the green bond credit spread; $P I_{i t-2}$ represents the environmental pollution index of the region where the green bond issuer is located; certificate $_{i t}$ denotes a virtual variable that represents whether or not it is third-party certified; $X_{i t}$ represents a set of bond characteristics, bond issuers, and the controlling variables of macroeconomic indicators, including maturity $_{i t}$ (bond maturity) 、 scale $_{i t}$ (size of bond issue) 、 $\operatorname{rank}_{i t}$ (bond rating) 、 putoption $_{i t}$ (bond repurchase right) 、roe it -1 (yield valve) 、 ebit $_{i t-1}\left(\right.$ EBITDA) 、 leverage ${ }_{i t-1}$ （ratio of assets to liabilities）、 fund $_{i t-1}$ (percentage of net cash generated from financing activities) 、GDP $P_{i t-1}$ 


\section{Empirical Results}

\subsection{Descriptive statistics}

Descriptive statistics are given in table 3. First, the average and median credit spreads are greater than zero, meaning that most credit spreads are positive. Second, $43 \%$ of green bonds have third-party certifications, the average maturity of the bonds is 2.29 years, the median is 5 years, and the maximum is 15 years, which indicates that most of the green bonds issued in China are medium-and long-term bonds, it indicates that the green bond issued by our country has a high credit rating.

Table 3 Descriptive Statistics

\begin{tabular}{ccccccc}
\hline variables & number & max & median & min & mean & sd \\
\hline$r_{g p}$ & 543 & 5.11 & 1.80 & 0.31 & 2.14 & 1.20 \\
$P_{t-2}$ & 543 & 1.00 & 0.06 & 0.00 & 0.13 & 0.19 \\
certificate & 543 & 1.00 & 0.00 & 0.00 & 0.43 & 0.50 \\
scale & 543 & 32.00 & 7.00 & 0.10 & 9.01 & 7.60 \\
maturity & 543 & 15.00 & 5.00 & 0.74 & 5.29 & 2.62 \\
rank & 543 & 4.00 & 4.00 & 0.00 & 2.97 & 1.48 \\
putoption $_{\text {roa }}$ & 469 & 1.00 & 0.00 & 0.00 & 0.36 & 0.48 \\
roa $_{t-1}$ & 543 & 11.75 & 2.15 & -23.69 & 2.81 & 3.87 \\
ebit $_{t-1}$ & 537 & 318.69 & 23.22 & -130.76 & 34.54 & 56.37 \\
leverage $_{t-1}$ & 534 & 107.99 & 62.01 & 7.65 & 59.16 & 17.61 \\
fund $_{t-1}$ & 540 & 382.83 & 0.13 & -6089.60 & -112.70 & 829.18 \\
GDP $_{t-1}$ & 534 & 6.95 & 6.11 & 2.30 & 5.02 & 2.01 \\
shibor $_{t-1}$ & 543 & 4.10 & 2.75 & 2.65 & 2.99 & 0.48 \\
index $_{t-1}$ & 543 & -1.87 & -13.82 & -29.53 & -11.67 & 9.77 \\
\hline
\end{tabular}

\subsection{Baseline regression result}

In order to control the year effect and the industry effect, two kinds of fixed effects, two-way fixed effect and combined fixed effect, are used in this paper. Table 4 shows the baseline regression results: the first four are the regression results of the two-way fixed effects model, and the last four are the regression results of the combined fixed effects. Column (1), column (2) and column (5), column (6) are the unit regression results of two core explanatory variables for the green bond credit spread $\left(r_{g p}\right)$ respectively, the Regional Environmental Pollution Index (env) is positive at the level of $10 \%$ significance in the two-way fixed-effect model, indicating that the lower the level of environmental pollution in the region, the lower the financing cost of issuing green bonds in the region, the baseline regression results support H1. Column (4) and column (8) are the regression results after controlling variables are added. According to the regression results of two kinds of fixed effect models, the regional Environmental Pollution Index has a positive effect on the green bond credit spread under the level of 5\% significance, that the lower the pollution level in a region, the lower the financing cost of issuing green bonds, which supports $\mathrm{H} 1$; that third party certification is significantly negative at a $10 \%$ confidence level, which means that third party certification reduces the green bond credit spread, $\mathrm{h} 2$ is supported by the fact that third party certification reduces the cost of financing green bonds.

Table 4 Baseline Regression Result

\begin{tabular}{|c|c|c|c|c|c|c|c|c|}
\hline \multirow[b]{2}{*}{ variables } & \multicolumn{4}{|c|}{ Bidirectional fixation effect } & \multicolumn{4}{|c|}{ Combined fixation effect } \\
\hline & $r_{g p}$ & $r_{g p}$ & $r_{g p}$ & $r_{g p}$ & $r_{g p}$ & $r_{g p}$ & $r_{g p}$ & $r_{g p}$ \\
\hline
\end{tabular}




\begin{tabular}{|c|c|c|c|c|c|c|c|c|}
\hline \multirow[t]{2}{*}{$P I_{t-2}$} & $0.506^{*}$ & & $0.539 *$ & $0.419 * *$ & 0.393 & & 0.420 & $0.366^{* *}$ \\
\hline & $(1.98)$ & & $(2.36)$ & $(2.85)$ & $(1.45)$ & & $(1.72)$ & (3.09) \\
\hline \multirow[t]{2}{*}{ certificate } & & -0.111 & -0.130 & $-0.184 *$ & & -0.102 & -0.116 & $-0.185^{*}$ \\
\hline & & $(-0.57)$ & $(-0.70)$ & $(-2.07)$ & & $(-0.47)$ & $(-0.55)$ & $(-1.96)$ \\
\hline \multirow[t]{2}{*}{ scale } & & & & $-0.037 * * *$ & & & & $-0.037 * * *$ \\
\hline & & & & $(-5.94)$ & & & & $(-3.68)$ \\
\hline \multirow[t]{2}{*}{ maturity } & & & & 0.012 & & & & 0.013 \\
\hline & & & & $(0.34)$ & & & & $(0.42)$ \\
\hline \multirow[t]{2}{*}{ rank } & & & & $-0.314 * * *$ & & & & $-0.316 * * *$ \\
\hline & & & & $(-5.85)$ & & & & $(-6.21)$ \\
\hline \multirow[t]{2}{*}{ putoption } & & & & 0.219 & & & & 0.240 \\
\hline & & & & $(0.74)$ & & & & $(0.76)$ \\
\hline \multirow[t]{2}{*}{$\operatorname{roa}_{t-1}$} & & & & $-0.071 * * *$ & & & & $-0.072 * * *$ \\
\hline & & & & $(-4.95)$ & & & & $(-4.94)$ \\
\hline \multirow[t]{2}{*}{ ebit $_{t-1}$} & & & & $-0.004 * *$ & & & & $-0.004 *$ \\
\hline & & & & $(-2.53)$ & & & & $(-2.16)$ \\
\hline \multirow[t]{2}{*}{ leverage $t-1_{1}$} & & & & -0.007 & & & & -0.007 \\
\hline & & & & $(-1.06)$ & & & & $(-1.41)$ \\
\hline \multirow[t]{2}{*}{ fund $_{t-1}$} & & & & $0.000^{*}$ & & & & -0.000 \\
\hline & & & & $(2.15)$ & & & & $(-0.22)$ \\
\hline \multirow[t]{2}{*}{$G D P_{t-1}$} & & & & -0.306 & & & & $-0.254 * * *$ \\
\hline & & & & $(-1.86)$ & & & & $(-3.79)$ \\
\hline \multirow[t]{2}{*}{ shibort-1 } & & & & -1.470 & & & & $0.916^{*}$ \\
\hline & & & & $(-1.02)$ & & & & $(2.07)$ \\
\hline \multirow[t]{2}{*}{ index $_{t-1}$} & & & & -0.111 & & & & -0.056 \\
\hline & & & & $(-1.65)$ & & & & $(-1.88)$ \\
\hline \multirow[t]{2}{*}{ Constant } & $0.917 * * *$ & $1.085^{* * *}$ & $1.058 * * *$ & $8.749^{*}$ & $2.377 * * *$ & $2.496 * * *$ & $2.492 * * *$ & 1.970 \\
\hline & $(8.06)$ & (4.06) & $(3.52)$ & (1.91) & $(205.75)$ & (11.63) & (11.61) & (1.37) \\
\hline Year & YES & YES & YES & YES & NO & $\mathrm{NO}$ & $\mathrm{NO}$ & NO \\
\hline Industry & YES & YES & YES & YES & NO & NO & NO & NO \\
\hline Year*Industry & NO & NO & $\mathrm{NO}$ & NO & YES & YES & YES & YES \\
\hline Observations & 543 & 543 & 543 & 528 & 543 & 543 & 543 & 528 \\
\hline$R^{2}$ & 0.130 & 0.126 & 0.132 & 0.484 & 0.184 & 0.182 & 0.186 & 0.516 \\
\hline $\operatorname{Adj} R^{2}$ & 0.100 & 0.096 & 0.101 & 0.456 & 0.099 & 0.097 & 0.099 & 0.457 \\
\hline
\end{tabular}

Note: $\mathrm{T}$ values in parentheses; $* *, * *, *$ are significant at $1 \%, 5 \%$, and $10 \%$ levels, respectively; in parentheses are regression results under the robust criteria of Cluster at the bond category level.

\subsection{Robustness test}

In this paper, we use the method of substitution dependent variable, independent variable and maximum likelihood to test the robustness.

\subsection{1 replace the interpreted variable}

This paper considers the credit risk of green bond, the linkage of corporate bond market and the impact of green bond market on the financing cost of single green bond, the credit spread of green bonds is replaced by the following three indicators: first, the interest rate of the green bond itself, and second, the difference between the interest rate of the green bond issue and the risk-free yield (take the one-year treasury bond interest rate issued in the current year as an example), namely the risk premium $\left(r_{p}\right)$, third, the difference between the interest rate of the green bond issue and the annualized yield of the full-price index of the Shanghai Stock Exchange corporate bonds in that year $\left(r_{b p}\right)$, and fourth, the difference between the interest rate of green bond issue and the 
annualized yield of CNB00013( $\left.r_{g m p}\right)$.

As can be seen from table 5, the results of the regression after the replacement of the explanatory variables are similar to the original, and the control variables are stable, so the benchmark regression is robust. Furthermore, in the two-way fixedeffect model, the third-party authentication significance increased to 5\%, and the significance of the joint fixed-effect model was consistent with the benchmark regression. At the same time, the goodness of fit of the model of the last three explained variables is gradually increasing, which indicates that the explaining strength of environment-friendly preference factors and other controlled variables is also increasing.

Table 5 The Regression Result of the Substitution Dependent Variable

\begin{tabular}{ccccccccc}
\hline & \multicolumn{3}{c}{ Bidirectional fixation effect } & \multicolumn{3}{c}{ Combined fixation effect } \\
variables & $r_{b}$ & $r_{p}$ & $r_{b p}$ & $r_{g m p}$ & $r_{b}$ & $r_{p}$ & $r_{b p}$ & $r_{g m p}$ \\
\hline PIt-2 & $0.528^{* *}$ & $0.528^{* *}$ & $0.528^{* *}$ & $0.528^{* *}$ & $0.487^{* *}$ & $0.487^{* *}$ & $0.487^{* *}$ & $0.487^{* *}$ \\
& $(3.04)$ & $(3.04)$ & $(3.04)$ & $(3.04)$ & $(3.20)$ & $(3.20)$ & $(3.20)$ & $(3.20)$ \\
certificate & $-0.243^{* *}$ & $-0.243^{* *}$ & $-0.243^{* *}$ & $-0.243^{* *}$ & $-0.247^{*}$ & $-0.247^{*}$ & $-0.247^{*}$ & $-0.247^{*}$ \\
& $(-2.47)$ & $(-2.47)$ & $(-2.47)$ & $(-2.47)$ & $(-2.25)$ & $(-2.25)$ & $(-2.25)$ & $(-2.25)$ \\
Constant & $14.833^{* *}$ & $10.023^{*}$ & $11.178^{*}$ & $-21.819^{* * *}$ & $3.215^{*}$ & 2.375 & $-6.757^{* * *}$ & -2.917 \\
& $(3.02)$ & $(2.04)$ & $(2.28)$ & $(-4.45)$ & $(2.04)$ & $(1.51)$ & $(-4.30)$ & $(-1.86)$ \\
\hline Controls & YES & YES & YES & YES & YES & YES & YES & YES \\
Year & YES & YES & YES & YES & NO & NO & NO & NO \\
Industry & YES & YES & YES & YES & NO & NO & NO & NO \\
Year*Industry & NO & NO & NO & NO & YES & YES & YES & YES \\
Observations & 543 & 543 & 543 & 528 & 543 & 543 & 543 & 528 \\
$R^{2}$ & 0.532 & 0.490 & 0.740 & 0.878 & 0.557 & 0.517 & 0.754 & 0.885 \\
Adj $R^{2}$ & 0.507 & 0.462 & 0.726 & 0.872 & 0.502 & 0.457 & 0.724 & 0.871 \\
\hline
\end{tabular}

Note: the values in parentheses are T values calculated under the robust criteria of the bond type Cluster; $* *, *$ $*$, * are significant at $1 \%, 5 \%$, and $10 \%$ levels, respectively.

\subsection{2 replace the core explanatory variable}

Table 6 shows the regression results for the replacement of the core explanatory variable, certification by third parties (certificate). In this paper, we put the explanatory variable of bigcertificate into the regression. From the results, we can get the following conclusions: first, we compare the results of the unit regression, we can see that the results of bigcertificate are more significant, the results of two-way fixed-effect regression are increased to $10 \%$, and the results of joint fixed-effect regression are increased to 5\%, comparing the results of baseline regression with the control variables before and after the substitution variables, the significance of the core explanatory variables in the two regression results is basically the same, and the control variables are stable, which shows the robustness of the regression results, a comparison of the regression coefficients between the pre-replacement core explanatory variable, certification by a third party (certificate), and bigcertificate, after the replacement, reveals that the regression coefficients for bigcertificate are significantly higher than for third-party certification (certificate), green bonds certified by the top three certification bodies have lower credit spreads and lower financing costs than those certified by other non-top three certification bodies, this is with Jiang and Fan (2020) the research conclusion is consistent.

Table 6 Replace the Core Explanatory Variable with The Regression Result

\begin{tabular}{ccccccccc}
\hline & \multicolumn{4}{c}{ Bidirectional fixation effect } & \multicolumn{4}{c}{ Combined fixation effect } \\
variables & $r_{g p}$ & $r_{g p}$ & $r_{g p}$ & $r_{g p}$ & $r_{g p}$ & $r_{g p}$ & $r_{g p}$ & $r_{g p}$ \\
\hline
\end{tabular}




\begin{tabular}{|c|c|c|c|c|c|c|c|c|}
\hline$P I_{t-2}$ & & & $\begin{array}{c}0.419^{* *} \\
(2.85)\end{array}$ & $\begin{array}{c}0.413^{* *} \\
(2.72)\end{array}$ & & & $\begin{array}{c}0.366^{* *} \\
(3.09)\end{array}$ & $\begin{array}{c}0.368^{* *} \\
(3.17)\end{array}$ \\
\hline certificate & $\begin{array}{l}-0.111 \\
(-0.57)\end{array}$ & & $\begin{array}{l}-0.184 * \\
(-2.07)\end{array}$ & & $\begin{array}{l}-0.102 \\
(-0.47)\end{array}$ & & $\begin{array}{l}-0.185^{*} \\
(-1.96)\end{array}$ & \\
\hline bigcertificate & & $\begin{array}{l}-0.296^{*} \\
(-1.98)\end{array}$ & & $\begin{array}{l}-0.195^{*} \\
(-2.08)\end{array}$ & & $\begin{array}{c}-0.335^{* *} \\
(-2.37)\end{array}$ & & $\begin{array}{c}-0.221 * * \\
(-2.37)\end{array}$ \\
\hline Constant & $\begin{array}{c}1.085^{* * * *} \\
(4.06)\end{array}$ & $\begin{array}{c}1.115^{* * * *} \\
(6.36)\end{array}$ & $\begin{array}{l}8.749 * \\
(1.91)\end{array}$ & $\begin{array}{l}9.126^{*} \\
(2.15)\end{array}$ & $\begin{array}{c}2.496 * * * \\
(11.63)\end{array}$ & $\begin{array}{c}2.729 * * * \\
(19.28)\end{array}$ & $\begin{array}{l}1.970 \\
(1.37)\end{array}$ & $\begin{array}{l}1.828 \\
(1.29)\end{array}$ \\
\hline Controls & NO & NO & YES & YES & $\mathrm{NO}$ & $\mathrm{NO}$ & YES & YES \\
\hline Year & YES & YES & YES & YES & NO & NO & NO & NO \\
\hline Industry & YES & YES & YES & YES & NO & NO & NO & NO \\
\hline Year*Industry & NO & NO & NO & NO & YES & YES & YES & YES \\
\hline Observations & 543 & 543 & 528 & 528 & 543 & 543 & 528 & 528 \\
\hline$R^{2}$ & 0.126 & 0.132 & 0.484 & 0.483 & 0.182 & 0.190 & 0.516 & 0.516 \\
\hline $\operatorname{Adj} R^{2}$ & 0.096 & 0.103 & 0.456 & 0.455 & 0.0973 & 0.106 & 0.457 & 0.456 \\
\hline
\end{tabular}

Note: the values in parentheses are $\mathrm{T}$ values calculated under the robust criteria of the bond type Cluster; **, * * , * are significant at $1 \%, 5 \%$, and $10 \%$ levels, respectively.

\subsection{3 maximum likelihood}

In order to further improve the robustness of the results of the benchmark regression, the least square regression model is replaced by the maximum likelihood model. The results of the maximum likelihood regression are given in table 7. The results of regression without control variables in the table are basically consistent with the results of baseline regression, but with control variables in the table, both the two-way fixedeffect model and the joint fixed-effect model, the significance of regional environmental pollution index (PI) increased to $1 \%$, the significance of third-party certification (certificate) increased to 5\%, and other control variables were stable. All the above regression results show that the results of the benchmark regression are robust.

Table 7 The Results of the Maximum Likelihood Regression

\begin{tabular}{ccccc}
\hline & \multicolumn{2}{c}{ Bidirectional fixation effect } & \multicolumn{2}{c}{ Combined fixation effect } \\
variables & $r_{g p}$ & $r_{g p}$ & $r_{g p}$ & $r_{g p}$ \\
\hline$P I_{t-2}$ & $0.539^{* *}$ & $0.419^{* * *}$ & $0.420^{*}$ & $0.366^{* * *}$ \\
& $(2.56)$ & $(3.13)$ & $(1.93)$ & $(3.50)$ \\
certificate & -0.130 & $-0.184^{* *}$ & -0.116 & $-0.185^{* *}$ \\
& $(-0.76)$ & $(-2.27)$ & $(-0.62)$ & $(-2.22)$ \\
Constant & $1.058^{* * *}$ & $8.749^{* *}$ & $2.492^{* * *}$ & 1.970 \\
& $(3.83)$ & $(2.10)$ & $(13.06)$ & $(1.55)$ \\
\hline Controls & NO & YES & NO & YES \\
Year & YES & YES & NO & NO \\
Industry & YES & YES & NO & NO \\
Year*Industry & NO & NO & YES & YES \\
Observations & 543 & 528 & 543 & 528 \\
$R^{2}$ & 0.132 & 0.484 & 0.186 & 0.516 \\
Adj $R^{2}$ & 0.101 & 0.456 & 0.0993 & 0.457 \\
\hline
\end{tabular}
*,* are significant at $1 \%, 5 \%$, and $10 \%$ levels, respectively.

The previous empirical study shows that regional environmental performance and 
environmental-friendly preferences such as third-party certification will affect the financing cost of green bonds, as the lower the regional environmental pollution index, the lower the cost of financing for green bonds; the higher the cost of financing for "Labelled" green bonds; and the lower the cost of financing for third-party certified green bonds. The following two questions will be discussed in this paper: first, will the influence of environment-friendly preference on green bonds change under different moderating effects? Second, what is the specific mechanism by which the characteristics of environment-friendly preference affect the financing cost of green bonds? To answer the first question, this paper will examine the asymmetry of the impact of environment-friendly preference on the financing cost of green bonds from two aspects: the heterogeneity of regional pollution and the heterogeneity of industry pollution. For the second question, this paper divides the impact mechanism of regional environmental performance and third-party certification into two groups, considering the impact of fiscal punishment mechanism, credit restraint mechanism, third-party certification tax relief mechanism and financing channel mechanism on the financing cost of green bonds.

\subsection{Regulatory effect}

\subsubsection{Regional pollution heterogeneity}

Research by Su and Lian (2018) found that under the impact of the Green Credit policy, enterprises in highly polluted areas will not only find it more difficult to obtain bank loans, but also their commercial credit will be weakened, the cost of its debt will rise; meanwhile, businesses in less polluted parts of the country will have more access to bank credit, and their business credit will increase, this shows that the higher the degree of regional pollution will be proportional to the difficulty and cost of corporate financing.

Table 8 presents the regression results for regional pollution heterogeneity. (2) rank (3) is the regression result of single environment-friendly variable under the regional pollution heterogeneity, the regional environmental pollution index $(P I)$ is significantly negative under the 5\% confidence level, but the third party certification (certificate) is not significant; Column (5) is the regression result of two environment-friendly variables under the heterogeneity of regional pollution when the control variables are added. The regional pollution index $(P I)$ is significantly negative at the level of $1 \%$ significance, and the absolute value of the coefficient is greater than the absolute value of the coefficient of the base regression, which shows that the highly polluted area has the function of amplifying the regional environmental pollution and raising the financing cost of the green bond, while the certification of the third party (certificate) has become insignificant, this indicates that the regional environmental pollution in the high pollution area has strengthened the function of punishing the financing cost of the green bond.

Table 8 Regression Results of Regional Pollution Heterogeneity

\begin{tabular}{ccccc}
\hline & $(1)$ & $(2)$ & $(3)$ & $(4)$ \\
variables & $r_{g p}$ & $r_{g p}$ & $r_{g p}$ & $r_{g p}$ \\
\hline$P I_{t-2}$ & $0.419^{* *}$ & & & \\
& $(2.85)$ & & & \\
certificate & $-0.184^{*}$ & & & \\
& $(-2.07)$ & & & $0.726^{* * * *}$ \\
$P I_{t-2} *$ district & & $0.609^{* *}$ & & $(4.27)$ \\
& & $(2.89)$ & & -0.249 \\
certificate*district & & & -0.196 &
\end{tabular}




\begin{tabular}{ccccc} 
Constant & $8.749^{*}$ & $9.140^{*}$ & $(-1.28)$ & $(-1.72)$ \\
& $(1.91)$ & $(2.20)$ & $(2.06)$ & $8.601^{*}$ \\
Controls & YES & YES & YES & YES \\
Year & YES & YES & YES & YES \\
Industry & YES & YES & YES & YES \\
Observations & 528 & 528 & 528 & 528 \\
$R^{2}$ & 0.484 & 0.483 & 0.481 & 0.490 \\
Adj $R^{2}$ & 0.456 & 0.456 & 0.454 & 0.463 \\
\hline
\end{tabular}

Note: district values 1 are high pollution areas and 0 are low pollution areas. Columns (1) and (2)-(4) contain values calculated under the robust standard error for bond-level clustering (Cluster) ; ***,* and * were significant at $1 \%, 5 \%$ and $10 \%$ respectively.

\subsubsection{Heterogeneity of industrial pollution}

Hou Jian et al (2020) found that heavy pollution industries are under great pressure from environmental regulation, and their financing constraints are stronger. It is difficult to obtain financing either through commercial credit or bank credit, financing costs are higher than in the green and green sectors.

Table 9 presents the regression results of heterogeneous regulation of industry pollution. Column (2) to column (3) is the regression result of the regulatory effect of regional pollution heterogeneity on a single environment-friendly variable. The regional environmental pollution index $(P I)$ is significantly positive at $1 \%$ confidence level, thirdparty certification (certificate) was also positive at $1 \%$ confidence level; column (4) is a regression of the regulatory effects of regional pollution heterogeneity on two environmentally friendly variables after the control variables were added, the area pollution index $(P I)$ was significantly positive at the level of $10 \%$ significance, and the absolute value of its coefficient was much larger than that of the standard regression, this suggests that highly polluting industries have the effect of amplifying regional environmental pollution and raising the cost of financing green bonds, while third party certification certification (certificate) has become less significant, this indicates that the regional environmental pollution of high pollution industries has strengthened the function of punishing the financing cost of green bonds.

Table 9 Regression Results of Heterogeneous Regulation Of Industrial Pollution

\begin{tabular}{ccccc}
\hline & $(1)$ & $(2)$ & $(3)$ & $(4)$ \\
variables & $r_{g p}$ & $r_{g p}$ & $r_{g p}$ & $r_{g p}$ \\
\hline$P I_{t-2}$ & $0.419^{* *}$ & & & \\
certificate & $(2.85)$ & & & \\
& $-0.184^{*}$ & & & \\
PIt-2* pollution $^{*}$ & $(-2.07)$ & & & $7.384^{*}$ \\
certificate* pollution & & $6.218^{* * *}$ & & $(1.72)$ \\
& & $(2.75)$ & & -0.168 \\
Constant & & & $0.466^{* *}$ & $(-0.38)$ \\
& & & $(2.27)$ & $9.064^{* * *}$ \\
Controls & & & & \\
Year & $(1.91)$ & $(4.55)$ & $(4.80)$ & $(4.55)$ \\
Industry & YES & YES & YES & YES \\
Observations & YES & YES & YES & YES \\
$R^{2}$ & YES & YES & YES & YES \\
Adj $R^{2}$ & 528 & 494 & 494 & 494 \\
& 0.484 & 0.493 & 0.489 & 0.493 \\
& 0.456 & 0.464 & 0.461 & 0.463 \\
\hline
\end{tabular}


Note: Pollution Value 1 is for high pollution industries, while value 0 is for low pollution industries. Columns (1) and (2)-(4) contain values calculated under the robust standard error for bond-level clustering (Cluster); ***, $*$ and $*$ were significant at $1 \%, 5 \%$ and $10 \%$ respectively.

\subsection{Mechanism analysis}

The model for the mechanism analysis used in this paper is as follows:

$$
\begin{gathered}
r_{\text {gpit }}=\alpha_{0}+\alpha_{1} \text { env }_{i t-1}+\alpha_{2} \text { green }_{i t}+\alpha_{3} \text { certificate }_{i t}+\gamma X_{i t}+\varepsilon_{i t} \\
\text { Medium }_{i t}=\beta_{0}+a_{1} \text { env }_{i t-1}+a_{2} \text { certificate }_{i t}+\beta_{1} \text { green }_{i t}+\gamma X_{i t}+\varepsilon_{i t} \\
r_{\text {gpit }}=\gamma_{0}+c_{1}^{\prime} \text { env }_{i t-1}+c_{2}^{\prime} \text { certificate }_{i t}+\text { bMedium }_{i t}+\gamma_{2}+\gamma_{C} X_{i t}+\varepsilon_{i t}
\end{gathered}
$$

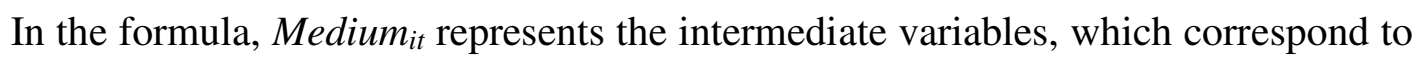
the variables of regional finance, regional credit, tax expenditure and bank loan respectively, and the control variables are consistent with the benchmark regression model. $a_{1}$ represents the total effect of the tax suppression mechanism and the credit punishment mechanism of the regional environmental performance, and a represents the total effect of the tax relief mechanism and the financing channel mechanism of the third party certification. $\mathrm{c} i$ is the direct effect of the tax suppression mechanism and the credit punishment mechanism of the regional environmental performance, $\mathrm{c}_{2}$ is the direct effect of the tax relief mechanism and the financing channel mechanism of the third party certification, $a_{1} * b$ is the intermediary effect of the tax suppression mechanism and the credit punishment mechanism of the regional environmental performance, and $a_{2} * b$ is the intermediary effect of the tax relief mechanism and the financing channel mechanism of the third party certification.

\subsubsection{Analysis on the mechanism of regional environmental performance}

\section{Regional tax restraint mechanism}

The uncertainty of economic policy in a region to some extent will increase the political risk of enterprises, especially for some enterprises with high emission, the easier it is for them to become the object of government's monitoring, thus increasing the tax revenue of the enterprises, similarly, the uncertainty of tax policy will aggravate the tax burden of enterprises and increase the financing cost of enterprises, while the uncertainty of fiscal tax policy and the decrease of fiscal revenue, increased pressure on local governments to increase revenue will also increase the cost of corporate financing. Liang et al. (2006) took taxation one step further by showing that implementing environmental taxes can not only improve the local environment and achieve sustainable development, but also increase income tax and labor-related tax revenue under the reduction, to improve the efficiency of economic development and promote economic growth. Local governments, then, are more willing to raise taxes under such incentives to achieve "Win-win" .

Table 10 shows the regression results of the regional tax penalty mechanism. The coefficient of the Environmental Pollution Index $\left(P I_{t-2}\right)$ in column (2) is significantly positive at the confidence level of $1 \%$, which indicates that the indirect effect of the intermediary effect exists and is positive. In column (3) the tax revenue growth $\left(\operatorname{Tax}_{t-2}\right)$ coefficient is significantly positive under the $1 \%$ confidence level, which indicates that the direct effect of the intermediary effect exists and is positive. Therefore, the regression result shows that the intermediary effect is positive, which shows that the regional environmental pollution increases the financing cost of the local enterprises issuing green bonds by reducing the local fiscal revenue.

Table 10 the Regression Result of Regional Tax Restraint Mechanism

\begin{tabular}{lccc}
\hline \multirow{2}{*}{ variables } & $(1)$ & $(2)$ & $(3)$ \\
& $r_{g p}$ & $\operatorname{Tax}_{t-2}$ & $r_{g p}$ \\
\hline$P I_{t-2}$ & $0.419^{* *}$ & $0.317^{* * *}$ & -0.130
\end{tabular}


$\operatorname{Tax}_{t-2}$

certificate

Constant

8.749*

0.059

Controls $\quad$ YES

(0.20)

(1.97)

\begin{tabular}{lccc} 
Year & YES & YES & YES \\
Industry & YES & YES & YES \\
Observations & 528 & 528 & 528 \\
$R^{2}$ & 0.484 & 0.434 & 0.499 \\
Adj $R^{2}$ & 0.456 & 0.403 & 0.471 \\
\hline
\end{tabular}

Note: the values in parentheses are $\mathrm{T}$ values calculated under the robust criteria of the bond type Cluster; **, * $*, *$ are significant at $1 \%, 5 \%$, and $10 \%$ levels, respectively.

2. Regional credit penalty mechanism

As early as July 2007, the SEPA, the People's Bank of China and the China Banking Regulatory Commission jointly issued The Opinions on Implementing Environmental Protection Policies and Regulations and Preventing Credit Risks, this marks the beginning of green credit policy as an important financial means of environmental governance. In January 2012, the former China banking regulatory commission issued Green Credit Guidelines, which formally put forward the concept and role of "Green Credit" and explicitly proposed the use of credit to promote energy conservation, emission reduction and environmental governance, we will guide the rational allocation of credit resources and accelerate the development of green industries and the restructuring of the economy. After the promulgation of the Green Credit policy, the regions with better environmental performance will get more credit resources, while the regions with worse environmental performance will have less credit resources. June Chan (2019) found that the "Two high one leftover" enterprise loans by the Green Credit Guidelines of the greater the impact of the repression, the higher the cost of financing. Green credit constraints are even more severe for heavily polluting enterprises and heavily polluted areas, and illiquid debt financing has declined significantly, which inhibits credit financing for heavily polluting enterprises and heavily polluted areas, resulting in an increase in credit financing costs. The cost of bond financing is also affected by other financing methods. Credit financing is an important financing method. When a regional environment performs well, when companies in a region have better access to bank credit resources, that is, when the cost of credit financing is lower, the cost of financing the issue of green bonds is correspondingly lower; and when a regional environment is performing poorly, companies in the region will find it more difficult to obtain credit from banks, which means that the cost of financing will be higher, as will the cost of other means, including green bonds.

Table 11 shows the regression results of regional tax penalty mechanisms. In column (2) the regression coefficient of the environmental pollution index $\left(P I_{t-2}\right)$ is significantly negative at $1 \%$ confidence level, which indicates that the indirect effect of the intermediate effect exists and is negative; The regression coefficient of the regional credit $\left(\operatorname{loan}_{t-1}\right)$ in column (3), loant-12, is significantly negative at $1 \%$ confidence level, indicating that the direct effect of the intermediary effect exists and is negative.

600 Therefore, the regression results show that the intermediary effect is positive, and that

601 regional environmental pollution leads to the increase of the cost of various financing 
methods by reducing the total amount of regional credit through regional environmental pollution, this has raised the cost of financing for local companies to issue green bonds.

Table 11 the Regression Result of Regional Credit Punishment Mechanism

\begin{tabular}{lccc}
\hline \multirow{2}{*}{ variables } & $(1)$ & $(2)$ & $(3)$ \\
\hline$P I_{t-2}$ & $r_{g p}$ & loan $_{t-1}$ & $r_{g p}$ \\
& $0.419 * *$ & $-1.106^{* * *}$ & $(1.94)$ \\
loan $_{t-1}$ & $(2.85)$ & $(-5.24)$ & $-0.248^{* *}$ \\
& & & $(-3.30)$ \\
certificate & & & $-0.191^{*}$ \\
& $-0.184 *$ & -0.027 & $(-2.28)$ \\
Constant & $(-2.07)$ & $(-0.39)$ & $10.394 * *$ \\
& $8.749 *$ & 6.621 & $(2.40)$ \\
\hline Controls & $(1.91)$ & $(1.78)$ & YES \\
Year & YES & YES & YES \\
Industry & YES & YES & YES \\
Observations & YES & YES & 528 \\
$R^{2}$ & 528 & 528 & 0.506 \\
Adj $R^{2}$ & 0.484 & 0.234 & 0.479 \\
\hline Note: the values in parentheses are T values calculated under the robust criteria of the bond type Cluster; **
\end{tabular}

\subsubsection{Analysis on the mechanism of the third-party authentication}

1. tax reduction and relief mechanism

In the traditional microeconomics hypothesis, the firm pursues profit maximization, that is to say, when the price is fixed, the firm pursues cost minimization under the condition of given output, and the firm pursues output maximization under the condition of given cost. Assuming that the economy is perfectly competitive and the firm produces only one product, the profit to be gained by the firm is:

Profit $=$ (unit price-unit cost $) *$ product sales

According to the theoretical analysis above, in real economic life, in order to prevent and control pollution, save energy and reduce emissions, and promote environmental protection, the government adopts administrative measures to achieve environmental achievements, in particular, the government uses administrative punishment, that is, fines or heavier taxes to control pollution, and uses administrative subsidies, such as government subsidies and tax breaks, to promote environmental protection. In this paper, for the sake of simplification, administrative fines are regarded as increasing tax revenue, while government subsidies are regarded as reducing tax revenue and taxing the price of individual products:

Profit $=($ unit product price-unit cost-unit product tax $) *$ product sales

The formula (13) shows corporate profits with taxes. When companies meet environmental requirements, they are more likely to receive tax breaks from the government, increase their profits, improve their financial position, have less difficulty in obtaining financing, and have lower financing costs.

Table 12 shows the regression results of the tax relief mechanism. In the column (2) the regression coefficient for third-party certification (certificate) was positive at the 5\% significance level, that is, the issuance of a third certified green bond can increase the financing constraint index $(F C)$, indicating that third-party certification can alleviate the financing constraint of the issuer, it shows that the indirect effect of intermediary effect exists and is positive, and the regression coefficient of the financing 
constraint index $(F C)$ is negative at the level of $1 \%$ significance, that is, the looser the financing constraint, the lower the financing cost of green bonds, it shows that the direct effect of mediating effect exists and is negative. Therefore, the result of regression shows that the intermediary effect is negative, which shows that the listed third party certification reduces the financing cost of the green bond issuers by easing the financing constraints of the issuers.

Tbale 12 The Regression Result of Tax Relief Mechanism

\begin{tabular}{lccc}
\hline \multirow{2}{*}{ variables } & $(1)$ & $(2)$ & $(3)$ \\
certificate & $r_{g p}$ & tax & $r_{g p}$ \\
\multirow{2}{tax}{} & $-0.184^{*}$ & $-0.067^{*}$ & $-0.245^{* *}$ \\
& $(-2.07)$ & $(-2.40)$ & $(-2.64)$ \\
$P I_{t-2}$ & & & $0.453^{* * *}$ \\
& & & $(6.09)$ \\
Constant & $0.419^{* *}$ & $0.285^{* * *}$ & $-0.851^{*}$ \\
& $(2.85)$ & $(7.67)$ & $(-2.18)$ \\
\hline Controls & $8.749^{*}$ & 2.307 & 6.754 \\
Year & $(1.91)$ & $(1.05)$ & $(1.81)$ \\
Industry & YES & YES & YES \\
Observations & YES & YES & YES \\
$R^{2}$ & YES & YES & YES \\
Adj $R^{2}$ & 528 & 253 & 253 \\
\hline
\end{tabular}

Note: the values in parentheses are $\mathrm{T}$ values calculated under the robust criteria of the bond type Cluster; $* *, *$ * , * are significant at $1 \%, 5 \%$, and $10 \%$ levels, respectively.

2. Financing channel mechanism

Enterprise's credit financing belongs to the enterprise debt financing channel, also is one of enterprise bond financing alternative ways. When Enterprises obtain more bank loans, which shows that their credit is rising, the availability of other debt financing is enhanced, the financing channels available to enterprises are gradually broadened, and their financing costs are correspondingly reduced. In particular, following the introduction of the Green Credit policy, the other debts of the enterprises that had access to green credit increased significantly while the cost of financing decreased. According to the above analysis, the third-party certification of green bonds meets the requirements of ESG, embodies the concept of green finance, and is one of the manifestations of corporate social responsibility in green credit policies, so the thirdparty certification can increase the bank loan, especially the green credit, thus widen the financing channel of the enterprise, and then reduce the financing cost of issuing the green bond.

Drawing on the research of Chen et al. (2019), this paper uses the bank loan index to measure whether the financing channels of enterprises are broadened or not:

$$
\text { bankloan }=\text { Ln(shortloan }+ \text { longloan })
$$

Where shortloan and longloan represent banks'short-term and long-term loans to businesses, respectively, with all variables measured in billion dollars.

Table 13 shows the regression results of the financing channel mechanism. In column (2) the regression coefficient for third-party certification (certificate) was positive at the 10 per cent significance level, that is, the issuance of a third-party certification green bond increased bank credit by bankloan, indicating that third-party certification increased bank credit for businesses; In column (3) the regression coefficient of the bankloan is negative at the $1 \%$ significance level, that is, the more bank credit the 
enterprise gets, the lower the financing cost of the green bond is, it shows that the direct effect of mediating effect exists and is negative. Therefore, the regression results show that the intermediary effect is negative, which shows that the issuance of the third-party certified green bonds enhances the credit of the issuer and increases the bank credit of the issuer, this reduces the financing cost of the green bond issuers.

Table 13 The Regression Result of Financing Channel Mechanism

\begin{tabular}{|c|c|c|c|}
\hline & (1) & (2) & (3) \\
\hline \multirow{3}{*}{$\frac{\text { variables }}{\text { certificate }}$} & $r_{g p}$ & bankloan & $r_{g p}$ \\
\hline & $-0.184 *$ & $0.678 * * *$ & -0.115 \\
\hline & $(-2.07)$ & (4.64) & $(-0.97)$ \\
\hline \multirow[t]{2}{*}{ bankloan } & & & $-0.229 * * *$ \\
\hline & & & $(-10.23)$ \\
\hline \multirow[t]{2}{*}{ certificate } & $0.419 * *$ & -0.122 & $-1.075^{* *}$ \\
\hline & $(2.85)$ & $(-0.12)$ & $(-3.67)$ \\
\hline \multirow[t]{2}{*}{ Constant } & $8.749 *$ & $10.399 * *$ & $8.847^{* *}$ \\
\hline & (1.91) & (3.24) & $(2.70)$ \\
\hline Controls & YES & YES & YES \\
\hline Year & YES & YES & YES \\
\hline Industry & YES & YES & YES \\
\hline Observations & 528 & 528 & 528 \\
\hline$R^{2}$ & 0.484 & 0.537 & 0.570 \\
\hline $\operatorname{Adj} R^{2}$ & 0.456 & 0.484 & 0.519 \\
\hline
\end{tabular}

\section{Conclusions and policy recommendations}

This paper shows that environment-friendly preference factors will affect the financing cost of green bonds, and the specific conclusions are as follows:

First, the degree of pollution in a region is positively correlated with the financing cost of green bonds in that region, and the high degree of pollution in that region has a disciplinary effect on the financing of green bonds issuing enterprises in that region, the environment-friendly areas, that is, the low-pollution areas, have an encouraging effect on the financing of the green bond issuers in these areas.

Second, the third-party certification contains more environmental information, investors prefer it, and the certified green bond financing costs are reduced, and thirdparty certified green bonds from the top three are cheaper to finance than those from other institutions.

Third, green bonds issued in highly polluted areas also magnify the impact of regional pollution on raising financing costs and weaken the role of third-party certification in reducing the financing costs of green bonds, enterprises in highpollution areas and high-pollution industries do not meet the requirements of social responsibility, their financing costs are higher.

Fourth, regional environmental pollution affects the financing cost of green bonds through fiscal penalty mechanism and credit restraint mechanism, that is, regional pollution index affects the financing cost of green bonds through increasing regional tax revenue and reducing the total amount of local credit, thus raising the financing cost for local enterprises to issue green bonds; at the same time, the third-party certification factors affect the financing cost of green bonds through the mechanism of tax relief and financing channels, that is, enterprises issue green bonds with third-party certification by reducing their tax expenses and widening their financing channels, thus reducing the 
financing cost of the main issue of green bonds.

According to the influence of environment-friendly preference factors on the financing cost of green bonds, this paper puts forward the following policy suggestions

\section{References} market.

First of all, improve the green bond market third-party certification system and information disclosure system. Improve the third party certification standards, so that both with the international track, and combined with national conditions. We will accelerate the formulation and verification of relevant standards for the disclosure of information on green bonds, truly reflect the funds invested in green bonds, that is, the operation of the projects, and allow more financial resources to be invested in projects that are in line with the catalogue of Green Bond support projects.

Second, foster institutional investors with environmentally friendly preferences. To guide investors to pay more attention to the environmental risks of the issuers of green bonds and capital operation projects, so that more funds will be invested in the environmental protection and low-carbon industries and less in the polluting industries, environmentally friendly preferences for realizing capital flows. Industries that meet the needs of long-term economic and social development, such as new energy industry, low-carbon transportation industry, environmental protection construction industry and other low-pollution and environmental protection industries, will be sustainable development; and not in line with economic development, causing greater damage to the environment of high pollution, high energy-consuming enterprises, will be eliminated.

Third, to give full play to the role of local governments, local governments should strengthen the supervision of polluting enterprises and subsidies to environmental protection enterprises, reduce the tax burden of environmental protection-oriented enterprises, and at the same time improve the local market environment and improve the local credit system, thereby reducing the financing cost of enterprises issuing green bonds.

Fourth, enterprises should practice the concept of social responsibility investment and implement the requirements of ESG. Enterprises need to implement the spirit of green financial policy and constantly strengthen their awareness of social responsibility, so as to conform to the trend of social sustainable development, tax expenditure can be reduced or exempted, financing channels can be broadened and more government subsidies can be obtained, thus reduces each kind of financing way including the Green Bond, the financing channel financing cost.

Antonio Díaz, Ana Escribano (2021) Sustainability premium in energy bonds. Energy Economics 95: 105-113.

Ba Shu-song, Li Yu-xiang, Zhang Bo (2019) Research on the influencing factors of local government bond issuance pricing --from the perspective of bank-government relationship. International Finance Research 07: 76-86.

Bernard Paranque,Christophe Revelli (2017) Ethico-economic analysis of impact finance: The case of Green Bonds. Research in International Business and Finance 47:57-66.

Chen Xingxing, Shi yaya, Song Xianzhong (2019) Green credit constraint, business credit and corporate environmental governance. International Finance Research 12: 13-22. 
Clapp C (2014) Climate finance: capitalising on green investment trends. Climate Policy 62:44-48.

David C Broadstock, Louis T W , Cheng (2019) Time-varying relation between black and green bond price benchmarks: Macroeconomic determinants for the first decade. Finance Research Letters 29:17-22.

Dragon Yongjun Tang,Yupu Zhang (2020) Do shareholders benefit from green bonds? Journal of Corporate Finance 61:101-127.

Elettra Agliardi, Rossella Agliardi (2021) Pricing Climate-Related Risks in the Bond Market. Journal of Financial Stability 420: 100-142.

Fang hongxing, Shi Jikun, Zhang Guangbao (2013) Property Right Nature, information quality and corporate bond pricing: Empirical evidence from Chinese capital market. Financial Research 04: 170-182.

Flavio Bazzana,Anna Zadorozhnaya,Roberto Gabriele (2018) The role of covenants in bond issue. The case of Russian companies Emerging Markets Review 36:1-18.

Gao Xiaoyan and Ji Wenpeng (2018) Issuer characteristics and credit spread of green bonds. The Science of Finance and Economics 11: 26-36.

He Zhigang, Zhou Quan, Lu Yiwen (2016) The impact of financial certification on bond financing cost: a case study of CCB. Stock Market Report 02 : 63-71.

Hou Jian, Chang Qingshan, Chen Jiancheng, Song Hongfeng (2020) Impact of manufacturing green transition on energy intensity from the perspective of environmental regulation. Environmental science 40: 4155-4166.

JA Mathews, S Kidney, K Mallon, M Hughes (2010) Mobilizing Private Finance to Drive an Energy Industrial Revolution. Energy Policy 37:3263-3265.

Jiang Feifan, Fan Longzhen (2020) Green Premium or green discount?-—A study on the credit spread of green bonds in China. Management modernization 40: 11-15.

Jiazhen Wang,Xin Chen,Xiaoxia Li,Jing Yu, Rui Zhong (2020) The market reaction to green bond issuance: Evidence from China. Pacific-Basin Finance Journal 60: 105-257.

Jin Jiayu, Han Liyan (2016) Development trend and risk characteristics of international green bond. International Finance Research, 11: 36-44.

Jin Penghui (2010) Corporate bond market development and social financing costs. Financial Research 03: 16-23.

Juan C, Reboredo, Andrea Ugolini (2020) Price connectedness between green bond and financial markets. Economic Modelling 88: 25-38.

June Chan (2019) Has China's Green Credit policy been implemented? -- An analysis based on the scale and cost of enterprise loans. Contemporary Finance and Economics 03: 118-129.

Liang Yanhua, Wang Jingfang, Yuan Caiyan (2006) Analysis on the win-win effect of environmental tax and its enlightenment to Chinese tax reform. Soft Science 01: 69-71.

Linh Pham, Toan Luu, Duc Huynh (2020) How does investor attention influence the green bond market? Finance Research Letters 35:101-133.

Ma Yaming, Hu Chunyang, Liu Xinlong (2020) Issuance of green bonds and enhancement of firm value: an intermediate effect test based on DID model. Financial Forum 25: 29-39.

Marcus Painter (2020) An inconvenient cost: The effects of climate change on municipal bonds. Journal of Financial Economics 135: 468-482.

Olivier David Zerbib (2016) The effect of pro-environmental preferences on bond prices: Evidence from green bonds. Procedia Engineering 145:180-187.

Piet Eichholtz et al (2019) Environmental performance and the cost of debt: Evidence from commercial mortgages and REIT bonds. Journal of Banking and Finance 102: 19-32.

Research Bureau of the People's Bank of China (2017) China Green Finance Development Report 2017.China Finance Press, Beijing.

Shang Hongtao, song Yaxi (2020) Dynamic incentive effect of environmental R \& D subsidy in Chinese New Energy Enterprises. Scientific and technological progress and countermeasures 37: 65-72.

Shi Yanping and Liu eping (2019) Property Right Nature, risk taking and corporate bond credit spread . East China Economic Management 33: 119-128.

Shi Yongdong, Tian Yuanbo (2016) Do the terms of the contract affect the bond price? Empirical study based on Chinese corporate bond market. Financial Research 08: 143-158.

Sonia Labatt, Rodney R White (2002) Environmental Finance Guide to Environmental Risk 
Assessmentand Financial Products.Canada:John Wily and Sons 323: 405-409. behavior of heavily polluted enterprises? Financial Research 12: 123-137.

Tan Dijun, Tian Yixiang, Huang Wenguang (2008) Liquidity Compensation, intramarket and cross-market 'liquidity transfer' behavior . Financial Research 09 : 23-43.

Tsung-Kang Chen, Hsien-Hsing Liao,Pei-Ling Tsai (2011) Internal liquidity risk in corporate bond yield spreads. Journal of Banking \& Finance 35:978-987.

Wu Hongyi, Yindesheng (2021) 'Reward' and 'Punishment' of Green Credit policy on corporate debt financing: An evaluation based on quasi-natural experiment. Contemporary Finance 02: 49-62.

Wulandari Febi, Dorothea Schäfer, Andreas Stephan, Chen Sun (2018) The impact of liquidity risk on the yield spread of green bonds. Finance Research Letters 27:53-59.

Yang Guochao, Pan Yuzhang (2019) Is trust priced? Evidence from the bond market. Financial Research 01: 35-53.

Yang Xiya, Shi Bao Feng (2020) Green bond issue pricing factors. Financial Forum 25: $72-$ 80.

Yijun Meng, Chao Yin (2019) Trust and the cost of debt financing. Journal of International Financial Markets 59:58-53.

Zhang Qi, Zheng Yao, Kong Dongmin (2019) Regional environmental governance pressure, top management experience and corporate environmental investment: A quasi-natural experiment based on ambient air quality standards (2012). Economic Research 54: 183-198.

Zhou Hong, Xu Zhaoming, Peng Lihua, Yang Mengmeng (2011) The impact of macroeconomic uncertainty on corporate bond credit risk in China: Based on 2007-2009 monthly panel data. Accounting Research 12: 41-45 + 97 . 